\title{
Reciprocal Questioning Method for Large Class Size
}

\author{
Surajkumar G. Kumbhar', S. R. Kumbhar ${ }^{2}$, S. T. Satpute ${ }^{3}$, R. B. Thombare ${ }^{4}$, A. B. Salunkhe \\ ${ }^{123}$ Automobile Engineering Department, RIT, Rajaramnagar. \\ ${ }^{4}$ Electronics and Tele-Communication Engineering Department, NMCOE, Peth. \\ ${ }^{5}$ Mechanical Engineering Department, AIT, Vita. \\ ${ }^{1}$ surajkumar.kumbhar@ ritindia.edu \\ ${ }^{2}$ sanjay.kumbhar@ritindia.edu \\ ${ }^{3}$ sanjay.satpute@ ritindia.edu \\ ${ }^{4}$ rachanathombare0990@gmail.com \\ 5 amit14588@gmail.com
}

\begin{abstract}
The ability to ask relevant questions is an important skill for students. It builds students' ability to develop focused questions from the undergone reading. The objective of this work is to build skills among students which are required to develop a questioning ability by forming questions from given engineering reading study material. To enhance reading comprehension with the perspective of Reciprocal Questioning (ReQuest), the author used this innovative teaching technique in the form of ReQuest for the automotive chassis course of third year B. Tech. engineering. The final result of that semester showed that the technique improves motivation and learning capability in the students. The results indicate that students can be provided with such a simple structured instructional ReQuest procedure between groups to achieve outcome-based learning. While supplementary research is desirable, for the suggestion on the design of engineering courses so lectures can be utilized properly in the favor of learning of students.
\end{abstract}

Keywords: ReQuest, Questioning ability, reading comprehension, instructional procedure

\section{Introduction}

Today a skill set of instructional activities is required which allows students to apply on course content, to take possession of self-learning, to use the technology meaningfully, and cooperate. Present education implicates either problem solving or preparation for the same. But teachers and academic institutions skip the problemformulating stage. The system offers direct facts and procedures to leaner deprived of a chance to improve own questioning ability and investigation. They may remember the things but not gaining the full-fledged understanding to apply in real life.

Reciprocal Questioning (ReQuest) provides instructions which help students internalize learning and leads to greater comprehension. In the ReQuest procedure students work in groups to discover the purpose of reading as instructed by a facilitator. They find themselves in a cooperative learning situation. The author tried a new method in a theory course where many students reply strikingly to the new method, and most of them never tried such one.

Corresponding Author

Surajkumar G. Kumbhar,

Automobile Engineering Department, RIT, Rajaramnagar surajkumar.kumbhar@ritindia.com

This is not the first time where reciprocal questioning is applied. Many researchers had applied it to enhance the ability of the student to learn effectively. Manzo [1] verified ReQuest by evaluating the improvements done by remedial students of age from 07 to 26 years old in one-to-one remediation. Its usefulness with remedial students under medical conditions had led to an interest in its parallel potentialities in classroom settings. This reciprocal questioning is a sub-step of reciprocal teaching. Oczuks [2] explained this scaffolded technique which is purely based on teacher modeling, student participation, and four tactics of a learner used to know the reading material. This includes predicting, questioning, clarifying, and summarizing. Though this was formerly intended for slow and scuffling learners.

Additionally, Helfeldt [3] presented the ReQuest as an instructional technique to support at-risk readers. It can independently apply the valuable metacognitive approach of self-questioning. It united elements from dual timeproven question focused methods like Reciprocal Questioning (ReQuest) and Question-Answer Relationships (QARs) Hence, a scope to more informal investigations is available where someone should inspire to attempt ReQuest with a larger group.

Many researchers [04-07] has been tried to modified and enhance the efficiency of the technique. Though a gap to apply this technique to large class sizes is revealed from the above literature. This forms a motivation and inspiration to perform ReQuest in larger class sizes to enhance the reading comprehension and acquaint students with skills of preparing focused questions.

This paper represents how a theory course can be taught in undergraduate education effectively using a studentcentered approach. The author applied the conventional question-answer method. This new concept of interaction within the group of students. The author wrote conclusions based on feedback obtained from the class on which this technique was applied.

\section{Development of the technique}

The ReQuest procedure is a teaching-learning method in which questions preparation out of given important reading material is used to endorse student learning to comprehend concepts and principles contrast to straight forward facts and concepts communication. In addition to course content, ReQuest encourages the improvement in the preparation of 
the focused questions, reading with a purpose, and communication. It can also provide opportunities for working in groups, assessing the reading stuff, and so-called life-long learning.

Any theory concept area can be easily adjusted to this. While some will vary between restraints, there are some features of good ReQuest stuff that excel arenas. The reading material must stimulate students to pursue an indepth understanding of concepts. The reading stuff should push students to make logical decisions and to defend themselves. The material should incorporate the relevant purpose of reading which connects the student with course/knowledge. As used in groups, the material needs a level of difficulty to confirm that the students must work in a team to read and distribute as necessary.

\section{The procedure of the technique}

The construction of defined instructions is a key step for the ReQuest procedure [8]. The key stage in the preparation of the questions and in-depth reading of the material for profound understanding. To implement this activity a plan of group activity is necessary and every student knows about what they have to be learned and what they have to do in it.

Step 01: Findings appropriate reading material- The first step is to search the relevant reading material related to the course syllabus. The facilitator or teacher plays a critical role to find out the significant stuff which challenges the logical ability of the readers as well as defendable for them.

Step 02: Group Formation- Secondly, the facilitator has to ask students to make groups in a heterogeneous manner. Heterogeneous in gender-wise, in leadership quality-wise, in communication skills-wise, in these sense students made groups of themselves.

Step 03: Material Distribution- In this step facilitator or teacher should distribute the same material between the groups by considering probable reading time.

Step 04: Reading (Fig. 1) - The facilitator should instruct students to read the same to know in-depth.

Step 05: Preparation of Questions-Answers (Fig. 1) - Every individual has to discuss own reading with teammates. After a group discussion, students will know the concepts and their linkages with each other. They have to start work accordingly for the question and answer preparation. The facilitator must give suggestions to the groups.

Step 06: Question-Answer session (Fig. 2) - One group will ask questions to another group whereas another group tries to answer them in short. This will go on till all the question answers will be performed in a team.

It looks like a simple procedure but creates excitement between the groups like a debate.

\section{Suitability of the technique}

Automotive Chassis System course needs to relate to the students' expectations, discipline and maintain their interest. The main objective of the course is to learn basic constructional features and operating principles of chassis systems. Also, a student should analyze the underlying mechanism of chassis systems and select the appropriate component or system for the typical vehicular application. These objectives reflect the simplicity of the course as a theoretical conceptual course, so the main purpose of learning this is the introduction of a ReQuest procedure in the progressive assessment.

\section{Implementation of the technique}

The author implemented this activity within 02 hours. The author made a plan of group activity and instructed students about all the aspects of the technique. This leads the student to know about learning outcomes and what is expected to do.

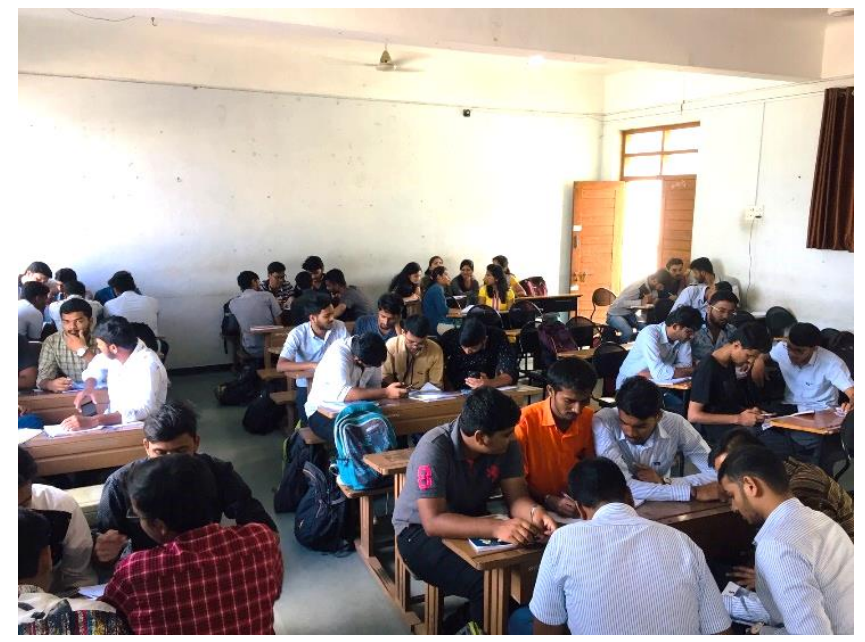

Fig. 1 Step 04 \& 05: Reading and Preparation of QuestionsAnswers

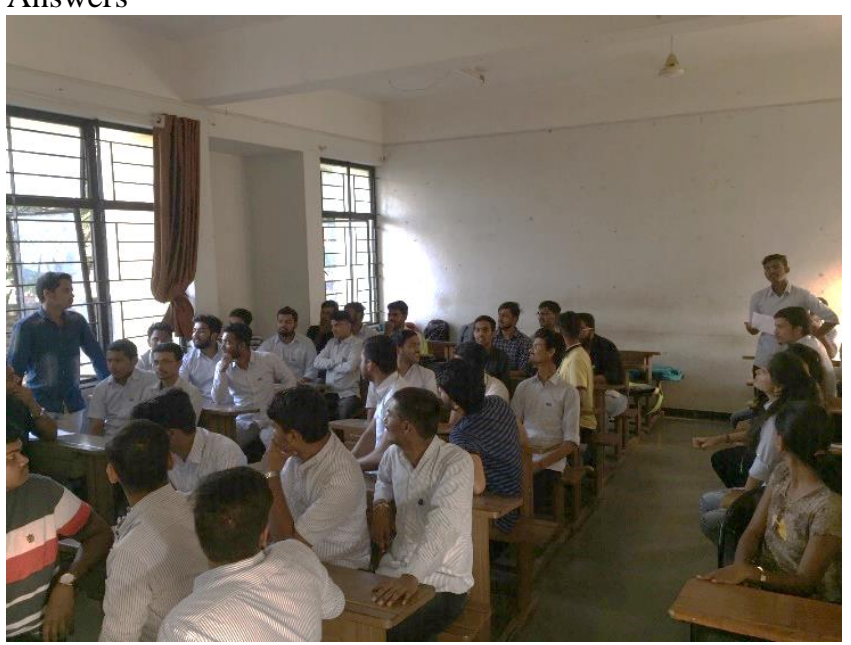

Fig. 2 Step 06: Question-Answer Session during ReQuest Procedure

The author already selected appropriate reading stuff from the course; which is challenging to comprehend and maximum questions can be prepared from the same. Then students instructed to form the teams on their own choice which takes 05 minutes so far. Wherever students tried to make their group homogenous, the facilitator interfered to make it heterogeneous. This is necessary to balance the 
potentials of the groups. Here, the material is distributed between the groups to start the reading session of 45 minutes. As the reading stuff is more compared to a single reader's ability to read out in 45 minutes, groups distributed the stuff among themselves within 03 to 04 minutes. This is instructed already that they can do the so as the activity has to be done in a group. Hence, it should go with the rule of proper distribution of the stuff. Groups read all the stuff and prepare the questions and answers. During the time, the facilitator performed the role of expert for the groups to revise the nature of the questions so that students should learn the techniques to prepare focused questions. This helps a lot to increases the ability of the student to think differently on the same stuff.

After all this, 15 minutes were given to discuss the group members among themselves. This coordinated the team and helpful for them to comprehend the overall concepts of the stuff. It is necessary as everyone was working on a different part of the stuff and only one chance to know the same. As students were discussing among themselves, they learn more which is the magic of the smallest generation gap. Students believe their friends more than their parents and teachers as usual as well as they tried their regional language to teach things which are very helpful to know the concepts. After all, this is the main motto of any kind of education.

The real play was started when the questions answer session was undergone. Each group got a chance to ask questions to another group. Similarly, each group was pushed to answer the questions. This made a healthy debate between them. As the questions were simple, straightforward and well planned. The teams took an interest during the activity. At the same time facilitator plays the role of evaluator. Each team got marks for each right answer and lose marks for the wrong one. It takes at least 45 to 60 minutes i.e., maximum time out of the whole given time. This was the heart of the technique as this is 'wow' moment of the play. Lastly, the winning team got appreciation from the facilitator and other team members.

A similar activity is performed for major and significant concepts or content of the course more than three times in the semester for the same course. This is due to the overwhelming response of the students to this active learning method.

\section{Difficulties faced in implementation}

Refining techniques to change the experience of theoretical courses for undergraduate education at universities is still a topic of conversation and research across the globe. Many concerns that teacher needs to be conscious while handling theory course has been the results of these debates and investigations. These include:

a) Students often find themselves bored while learning theory courses and detaching until they achieve and navigate own way into a challenging new learning environment posed by the facilitator. b) Students didn't know about learning practices that have to be followed for understanding theoretical concepts.

c) The multiplicity of experiences and their range gain by students when entered into the learning environment.

d) A struggle of expectations between teachers and students regarding knowledge conveyed.

\section{Results and Discussion}

Feedback of students revealed that the majority of students' agreed to "ReQuest" helped them create interest, better understanding \& promote self-directed subject learning. Students had given an average grade in feedback is 8 out of 10 (Table 1). Significant feedback statements are stated as the questioning ability is improved and overall performance is uplifted.

Table 1. Feedback of students on ReQuest

\begin{tabular}{|c|c|}
\hline $\begin{array}{c}\text { Learning rate } \\
\text { (on 10 point scale) }\end{array}$ & $\begin{array}{c}\text { No. of Students rated } \\
(\%)\end{array}$ \\
\hline 10 & 20 \\
\hline 09 & 14 \\
\hline 08 & 46 \\
\hline 07 & 12 \\
\hline $05-06$ & 08 \\
\hline
\end{tabular}

The ReQuest procedure is simple, short, or they can be more involved and take one or two hours. It is possibly implemented as a group-oriented activity, so it is beneficial to set aside classroom time to prepare students to work in groups and to allow them to engage.

Assessment and evaluation were simple as facilitator assigned marks while groups were performing the questionanswer session. This is because the facilitator goes into the role of the assessor and had time to do so easily. This instructional technique does not require any rubrics as in regular active learning technique requires. For each correct answer, group members will get full marks and vice versa. Feedback was taken from teams after the activity. In this, they gave exciting remarks over the technique. They agreed to have fun and learning through the exciting session. They requested to arrange more and more sessions on the same platform. This encourages them to perform the same ingroup study to check out the understanding of the member. 


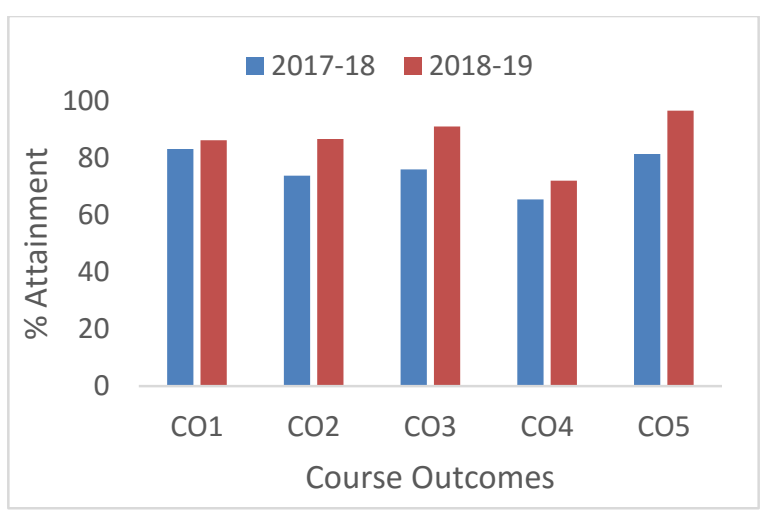

Fig. 3 Comparison of the Course attainment of the respective course for subsequent years

To test the efficacy of the method, the course attainment of the substantial years is compared in Fig 3. The course attainment comparison clearly shows the effectiveness of the technique to enhance the skillsets of the students. More than a $10 \%$ increase has been observed in the overall attainment of the course for the subsequent years.

\section{Conclusion}

A ReQuest, the instructional procedure is demonstrated for the large class size. Substantial improvement in the learning level reflected in the feedback taken reveals the acceptance of ReQuest procedure over conventional learning. Student comments over the technique are nothing but a piece of evidence showing popularity in the students, associated with better reading-questioning skills, that promote lifelong learning skills and probably do not sacrifice important areas of knowledge. Also, it does not need any additional resources compared with modern active learning approaches which show the simplicity and effectiveness of the technique. Continuous implementation of the important concepts of the course enhanced the student reading comprehension and questioning ability is reflected from the improvement observed in the course attainment. This paper uses the authors' experiences in implementing this technique. In particular, these activities developed in the Department of Automobile Engineering, Rajarambapu Institute of Technology, Rajaramnagar, Maharashtra (India) since 2018.

\section{Acknowledgment}

The authors would like to acknowledge the efforts of students and faculties of the Automobile Engineering Department at the RIT, Rajaramnagar.

\section{References}

[1] Manzo A. (1969) The ReQuest Procedure, Journal of Reading, 13, 123-127.

[2] Oczuks, L. (2003) Reciprocal teaching at work: Strategies for improving reading comprehension. Newark, DE: International Reading Association.
[3] John P. Helfeldt and William A. HenkSource (1990) Answer Relationships: An Instructional Technique for At-Risk Readers, Journal of Reading, 33 (7), 509-514.

[4] Ahmadi, Mohammad \& Pourhosein Gilakjani, Abbas. (2012). Reciprocal Teaching Strategies and Their Impacts on English Reading Comprehension. Theory and Practice in Language Studies. 2. 10.4304/tpls.2.10.2053-2060.

[5] Ersianawati, NL \& Santosa, Made \& Suprianti, Gap. (2018). Incorporating reciprocal questioning strategy and numbered heads together in reading class. International Journal of Language and Literature. 2. 10.23887/ij1l.v2i1.16090.

[6] Annemarie Sullivan Palincsar and Ann L. Brown, (1984) Reciprocal Teaching of ComprehensionFostering and Comprehension-Monitoring Activities, Cognition, and Instruction, 01 (2), 117-175.

[7] Barak Rosenshine, Carla E. Meister, (1993) Reciprocal teaching: a review of 19 experimental studies, Technical Report No. 574, University of Illinois at Urbana-Champaign.

[8] Tompkins, G. (1998). 50 literacy strategies: Step by step. Upper Saddle River, NJ: Prentice-Hall. 